\title{
A UFSM É UMA UNIVERSIDADE SUSTENTÁVEL?
}

http://dx.doi.org/10.5902/2318133840372

\author{
Marina Fonseca Seelig Falcão ${ }^{1}$ \\ Andressa de Oliveira Silveira²
}

Resumo

A Universidade Federal de Santa Maria - UFSM - tem por missão construir e difundir conhecimento de modo sustentável. Mas como saber se suas práticas são suficientes para que ela possa se dizer sustentável? O objetivo deste trabalho é avaliar o desempenho do campus da UFSM pelo GreenMetric: um modelo de medição do desempenho sustentável para universidades que divulga anualmente os resultados de seus usuários registrados na forma de um ranking. Os resultados por categoria, em escala de um a dez, foram: energia e mudanças climáticas 2,7; ensino e pesquisa 5,0; mobilidade 5,0; resíduos 7,5; espaço físico 5,5; água 2,0. A medida do desempenho resultou 4,8. Considerando o método de avaliações de conhecimento da universidade, cuja nota mínima é cinco, a medida de 4,8 é insuficiente para caracterizar a UFSM enquanto sustentável.

Palavras-chave: sustentabilidade; Greenmetric; medição de desempenho.

\section{IS UFSM A SUSTAINABLE UNIVERSITY?}

\begin{abstract}
Universidade Federal de Santa Maria - UFSM - has the mission of building and diffusing knowledge in a sustainable manner. But how can it know if its practices are enough for it to be called sustainable? The aim of this study is to evaluate the performance of UFSM's city campus by GreenMetric: a sustainability performance measurement model for universities that annually ranks its users. Results by category, on a scale from one to ten, were: energy and climate change 2.7, education and research 5.0, transportation 5.0, waste 7.5, setting and infrastructure 5.5, and water 2.0. The measure of the sustainability performance resulted in 4.8 points. Considering the university's knowledge assessment methodology, which has a minimum grade of five points, the measure of 4.8 points is insufficient.
\end{abstract}

Keywords: sustainability; Greenmetric; performance measurement.

\footnotetext{
1 Universidade Federal de Santa Maria, Brasil. E-mail: marinaseelig@gmail.com.

2 Universidade Federal de Santa Maria, Brasil. E-mail: andressa.silveira@ufsm.br.

\begin{tabular}{|l|l|l|l|l|r|}
\hline Regae: Rev. Gest. Aval. Educ. & Santa Maria & v. 9 & n. 18 & Pub. contínua 2020 & p. 1-16
\end{tabular}
}




\section{Introdução}

7 esde o início da década de 2000 a sustentabilidade se consolidou como a força propulsora de novos modelos de negócio, equilibrando valores econômicos, sociais e ambientais (Sebrae, 2013). O caráter de sustentável é buscado por empreendimentos de diversos ramos de atividade, inclusive educação: a Universidade Federal de Santa Maria - UFSM -, por exemplo, tem por missão "construir e difundir conhecimento, comprometida com a formação de pessoas capazes de inovar e contribuir com o desenvolvimento da sociedade, de modo sustentável" (UFSM, 2016, p. 18).

O conceito de sustentabilidade é complexo e contínuo:

O termo sustentabilidade é utilizado, mas pouco explicado. É de natureza conceitual, mal compreendido. Trata-se de um acessório de moda ou um senso comum. Há inconsistente interpretação e aplicação, alto grau de ambiguidade do conceito, incluindo uma percepção incompleta dos problemas de pobreza, degradação ambiental e o papel do crescimento econômico. E a situação não tem melhorado até então, continua sendo um slogan popular e brilhante. (Sartori; Latronico; Campos, 2014, p. 2)

O termo sustentabilidade tem origem na ecologia, expressando as condições necessárias para que um ecossistema se mantenha a longo prazo. Já o termo desenvolvimento sustentável surgiu em 1987 na publicação do Nosso futuro comum, conhecida como Relatório Brundtland da Comissão Mundial sobre o Meio Ambiente e Desenvolvimento das Nações Unidas (Holden; Linnerud; Banister, 2014; Sartori; Latronico; Campos, 2014). Neste relatório

desenvolvimento sustentável é o desenvolvimento que encontra as necessidades atuais sem comprometer a habilidade das futuras gerações de atender suas próprias necessidades. [...] $\mathrm{Na}$ sua essência, o desenvolvimento sustentável é um processo de mudança no qual a exploração dos recursos, o direcionamento dos investimentos, a orientação do desenvolvimento tecnológico e a mudança institucional estão em harmonia e reforçam o atual e futuro potencial para satisfazer as aspirações e necessidades humanas. (ONU Brasil, 2019)

Holden, Linnerud e Banister (2014) explicam que alguns autores diferenciam os dois termos, com a sustentabilidade sendo a dimensão ambiental do desenvolvimento sustentável ou com a sustentabilidade sendo o processo e o desenvolvimento sustentável a meta. Independentemente disso, aqui será adotada a compreensão discutida por Sartori, Latronico e Campos (2014, p. 5) de que ambos "objetivam passar para as gerações futuras um estoque de capital que é pelo menos tão grande quanto o que nossa própria geração herdou das gerações anteriores" (p. 5), e que "os valores, a política e nosso entendimento da Terra e seus sistemas irão evoluir, e as noções do que é sustentável nunca serão estáticas" (p. 5).

A questão da sustentabilidade nas instituições de ensino ganhou ênfase com a Década das Nações Unidas de Educação para o Desenvolvimento Sustentável, entre 2005 e 2014. A educação superior tem um papel estratégico, pois as instituições de ensino superior "representam um importante espaço social para reflexão, formação e 
difusão de novas concepções de desenvolvimento e sustentabilidade" (Rupea, 2007, p. 25). As universidades devem considerar a sustentabilidade internamente, como organizações, e externamente, como agentes de transformação regional (Dagiliūté; Liobikienè; Minelgaitè, 2018).

Velazquez et al. (2006) compuseram um modelo de gestão para sustentabilidade em universidades baseado em informações de oitenta instituições de ensino superior ao redor do mundo. No seu entendimento

uma instituição de ensino superior que aborda, pratica e promove - seja de modo integral ou parcial, em escala regional ou global - a minimização dos efeitos prejudiciais ao meio ambiente, à economia, à sociedade e à saúde quando faz uso de recursos para cumprir suas funções de ensino, pesquisa, extensão e parcerias institucionais, assim como se mostra liderança na transição social rumo a estilos de vida sustentáveis. (Velazquez et al., 2006, p. 812)

Contudo, quanto minimizados devem ser esses efeitos para que a universidade possa se dizer sustentável? Como medir a suficiência de suas práticas de sustentabilidade? Uma maneira objetiva é a utilização de indicadores de desempenho, levantando a situação real e comparando-a com um padrão previamente estabelecido e acordado. A utilização de medidas de desempenho é interessante, pois, como aponta Harrington (1993), o que não se pode medir não se pode controlar, não controlando não se pode gerenciar e sem gerenciamento não há melhoria.

No tocante à educação superior há diversos modelos de medição do desempenho sustentável específicos para universidades, destacando-se o GreenMetric, que divulga anualmente os resultados de seus usuários registrados na forma de um ranking, se apresentando como um ranking universitário internacional de ações de sustentabilidade. O modelo tem 39 indicadores de desempenho estruturados em seis categorias: energia e mudanças climáticas; ensino e pesquisa; mobilidade; resíduos; espaço físico; água. Em 2018 foram 719 universidades participantes, com a holandesa Universidade de Wageningen na primeira colocação. Das vinte e três universidades brasileiras participantes, a Universidade de São Paulo foi a mais bem colocada, em 23익 lugar. Duas universidades gaúchas participaram: a Pontifícia Universidade Católica do Rio Grande do

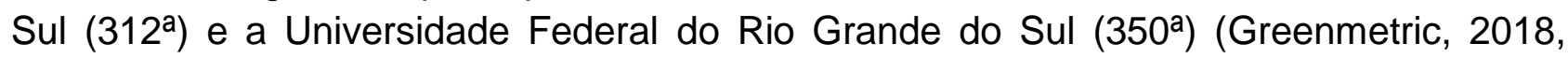
2019).

E qual é o desempenho sustentável da UFSM? Este trabalho visa a responder qual é a medida da sustentabilidade da UFSM no campus sede pela ótica do GreenMetric.

A visão da UFSM é ser reconhecida como uma instituição de excelência na construção e difusão do conhecimento, comprometida com o desenvolvimento da sociedade, de modo inovador e sustentável. A gestão ambiental e a internacionalização estão entre os sete desafios institucionais definidos para a UFSM no Plano de Desenvolvimento Institucional 2016-2026 (UFSM, 2016). Atualmente a UFSM não participa do ranking GreenMetric. Sua participação em tal ranking universitário internacional de ações de sustentabilidade estaria alinhada com o desenvolvimento da universidade. 


\section{Metodologia}

A Universidade Federal de Santa Maria está sediada em Santa Maria/RS. Foi a primeira universidade federal criada no interior do Brasil, em 1960. É a maior universidade federal do interior do Rio Grande do Sul: são 265 cursos, 27.664 alunos, 2.063 docentes e 2.680 técnico-administrativos em educação ${ }^{3}$. Além do campus sede há três campi: Frederico Westphalen, Palmeira das Missões e Cachoeira do Sul. A maior parte de suas atividades acadêmicas e administrativas acontece em Santa Maria. O território da UFSM é de aproximadamente onze quilômetros quadrados. O campus possui a configuração de uma verdadeira cidade, inclusive padecendo de problemas urbanos comuns a diversos municípios da região e do país (UFSM, 2016, 2019; Valentini, 2010). A figura 1 mostra o território da UFSM em Santa Maria, que é dividido em campus I, com 521,85ha, campus II, com 602,19ha, e Avenida Roraima, com 4,62ha. O Campus I é a zona urbana, onde são desenvolvidas as atividades de ensino e pesquisa e onde estão os prédios administrativos, salas de aula e laboratórios, e o Campus II é a zona rural, destinada às atividades das ciências agrárias. Foi considerado como área de estudo o campus I.

Figura 1 -

Campus no contexto urbano do município de Santa Maria.

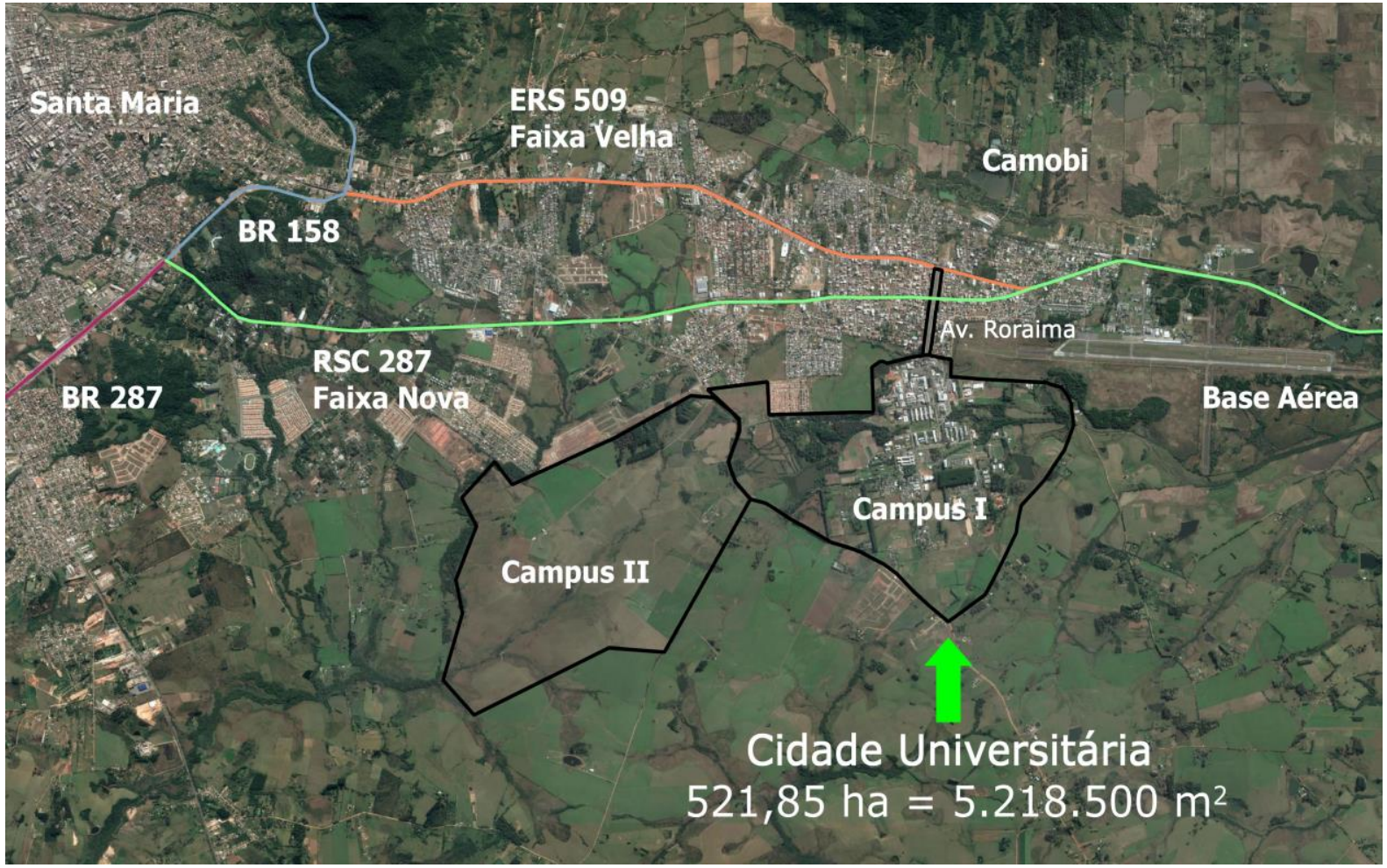

Fonte: Falcão (2018).

Os indicadores foram quantificados durante os meses de outubro e novembro de 2018. A busca pelos dados foi orientada pelo Setor de Planejamento Ambiental da universidade, ligado à Coordenadoria de Obras e Planejamento Ambiental e Urbano da Pró-Reitoria de Infraestrutura. A maioria dos dados foi obtida por questionamento direto ao setor responsável pelo tema do indicador. Alguns dados não eram de conhecimento da universidade, então foram estimados. Alguns indicadores referem-se à população do

3 Dados de 3 de outubro de 2019 do Portal UFSM em Números (UFSM, 2019)

\begin{tabular}{|l|l|l|l|l|r|} 
Regae: Rev. Gest. Aval. Educ. & Santa Maria & v. 9 & n. 18 & Pub. contínua 2020 & p. 1-16 \\
\hline
\end{tabular}


campus, dada pela soma do número de estudantes matriculados no ensino presencial e servidores - docentes, técnicos administrativos em educação e terceirizados -, na época contabilizada 23.935 pessoas. A circulação diária no campus, porém, gira em torno de quarenta mil pessoas, em função da presença do Hospital Universitário de Santa Maria, administrado pela Empresa Brasileira de Serviços Hospitalares.

Na figura 2 mostra-se o fluxograma da avaliação realizada. $O$ resultado de cada um dos 39 indicadores quantificados foi classificado de acordo com os níveis de referência de boas práticas de sustentabilidade para o indicador (0\%, 25\%, 50\%, 75\%, 100\%), obtendose uma respectiva pontuação para cada indicador. A pontuação dos indicadores de cada categoria foi somada, obtendo-se a pontuação de cada uma, que foi convertida em uma porcentagem para a avaliação do desempenho sustentável da universidade em cada categoria. A soma da pontuação das categorias deu a pontuação total, também convertida em uma porcentagem de sustentabilidade para avaliação: a medida do desempenho sustentável da cidade universitária da UFSM. A avaliação dos resultados em suficiente e insuficiente seguiu o método de avaliações de conhecimento da universidade (UFSM, 2015): a nota mínima de aprovação é cinco - desempenho 50\%, suficiente -, sendo desejável a nota mínima sete: desempenho $70 \%$.

Figura 2 -

Fluxograma da avaliação do desempenho sustentável do campus I.

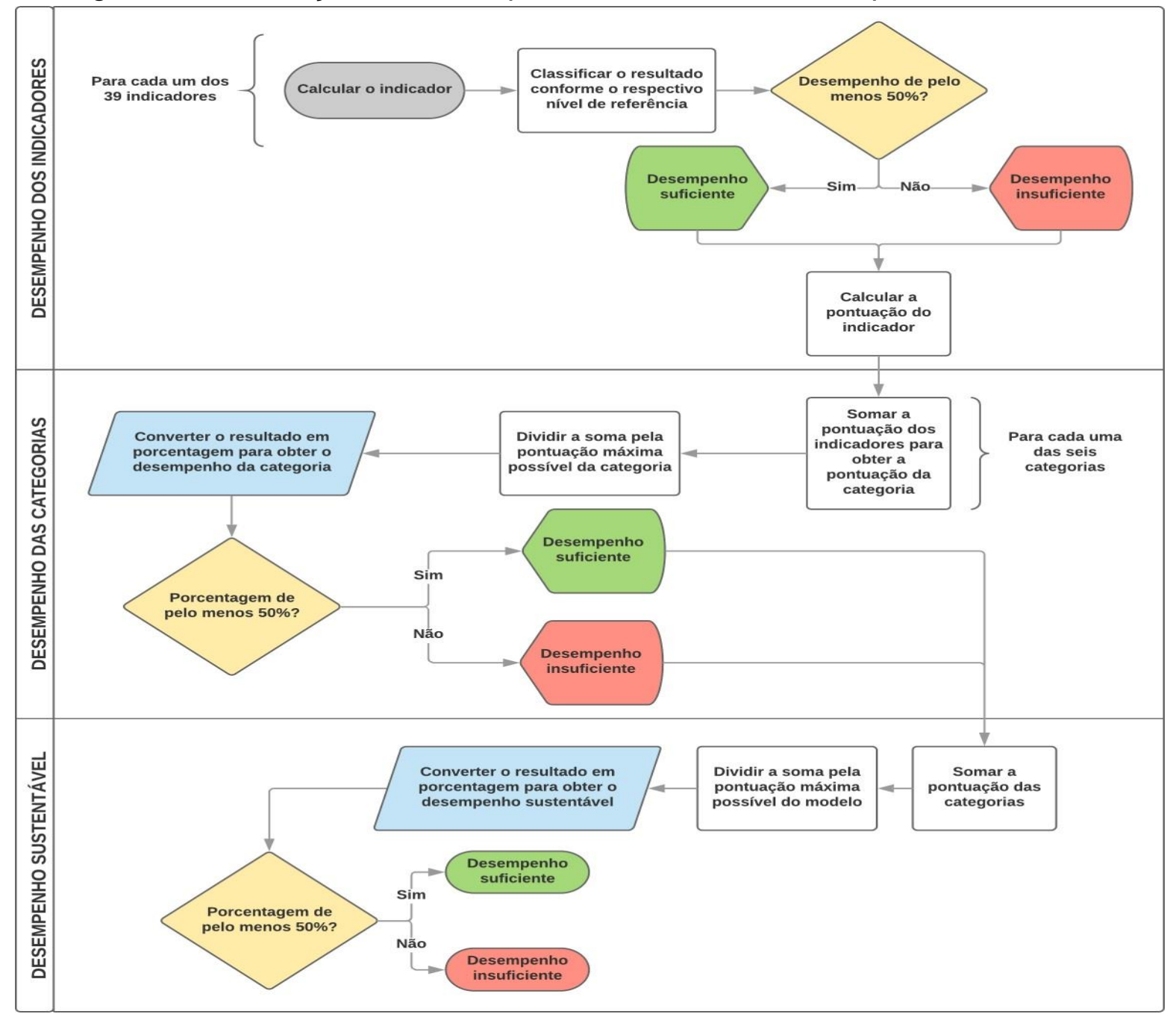

Fonte: Falcão (2018). 


\section{Resultados e discussão}

Os quadros a seguir apresentam os indicadores do modelo de medição, destacados por cor os resultados e desempenhos da UFSM em cada categoria: verde suficiente, vermelho insuficiente). Explicações sobre cada indicador são encontradas no guia do modelo (UI Greenmetric, 2018).

O quadro 1 refere-se à categoria Energia e mudanças climáticas. Dos oito indicadores três obtiveram desempenhos suficientes e cinco obtiveram desempenhos não suficientes, sendo quatro com desempenho $0 \%$. A gestão de energia na universidade é dificultada pela não individualização da medição de energia elétrica dos prédios, ação básica para campanhas educativas em economia de energia. Há aproveitamento de fontes renováveis de energia no campus, porém, o gerado é ínfimo diante do consumido. Ainda, institucionalmente, falta uma política de construções e reformas com elementos de edifícios verdes e um programa de redução de emissão de gases de efeito estufa.

\section{Quadro 1 -}

Indicadores na categoria Energia e mudanças climáticas.

\begin{tabular}{|c|c|c|c|}
\hline Código & Indicador & Nível & Pontuação \\
\hline EC1 & $\begin{array}{l}\text { Iluminação energeticamente eficiente } \\
\text { 1) }<1 \% \\
\text { 2) } 1-25 \%(8 \%) \\
\text { 3) } 25-50 \% \\
\text { 4) } 50-75 \% \\
\text { 5) }>75 \%\end{array}$ & $\begin{array}{c}0 \% \\
25 \% \\
50 \% \\
75 \% \\
100 \%\end{array}$ & $\begin{array}{c}0 \\
50 \\
100 \\
150 \\
200\end{array}$ \\
\hline EC2 & $\begin{array}{l}\text { Edifícios inteligentes } \\
\text { 1) }<1 \%(0 \%) \\
\text { 2) } 1-25 \% \\
\text { 3) } 25-50 \% \\
\text { 4) } 50-75 \% \\
\text { 5) }>75 \%\end{array}$ & $\begin{array}{c}0 \% \\
25 \% \\
50 \% \\
75 \% \\
100 \%\end{array}$ & $\begin{array}{c}0 \\
75 \\
150 \\
225 \\
300\end{array}$ \\
\hline EC3 & $\begin{array}{l}\text { Aproveitamento de fontes renováveis de energia } \\
\text { 1) Nenhuma fonte aproveitada } \\
\text { 2) Uma fonte aproveitada } \\
\text { 3) Duas fontes aproveitadas } \\
\text { 4) Três fontes aproveitadas } \\
\text { 5) Mais de três fontes aproveitadas }\end{array}$ & $\begin{array}{c}0 \% \\
25 \% \\
50 \% \\
75 \% \\
100 \% \\
\end{array}$ & $\begin{array}{c}0 \\
75 \\
150 \\
225 \\
300 \\
\end{array}$ \\
\hline EC4 & $\begin{array}{l}\text { Consumo de energia elétrica } \\
\text { 1) }>2424 \mathrm{kWh} / \text { pessoa } \\
\text { 2) } 1535-2424 \mathrm{kWh} / \text { pessoa } \\
\text { 3) } 633-1535 \mathrm{kWh} / \text { pessoa }(664,35 \mathrm{kWh} / \text { pessoa) } \\
\text { 4) } 279-633 \mathrm{kWh} / \text { pessoa } \\
\text { 5) }<279 \mathrm{kWh} / \text { pessoa }\end{array}$ & $\begin{array}{c}0 \% \\
25 \% \\
50 \% \\
75 \% \\
100 \% \\
\end{array}$ & $\begin{array}{c}0 \\
75 \\
150 \\
225 \\
300\end{array}$ \\
\hline EC5 & 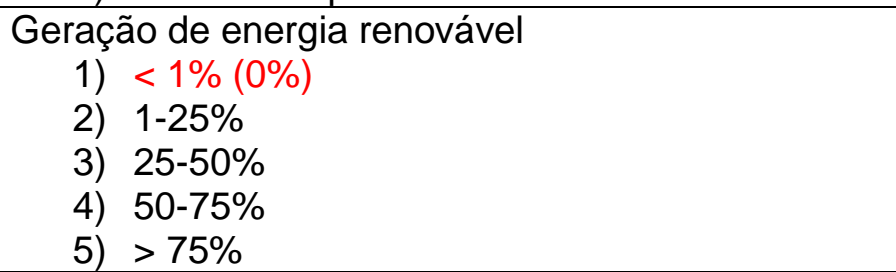 & $\begin{array}{c}0 \% \\
25 \% \\
50 \% \\
75 \% \\
100 \% \\
\end{array}$ & $\begin{array}{c}0 \\
50 \\
100 \\
150 \\
200\end{array}$ \\
\hline
\end{tabular}




\begin{tabular}{|c|c|c|c|}
\hline EC6 & $\begin{array}{l}\text { Edifícios verdes } \\
\text { 1) Nenhum elemento implantado } \\
\text { 2) Um elemento implantado } \\
\text { 3) Dois elementos implantados } \\
\text { 4) Três elementos implantados } \\
\text { 5) Mais de três elementos implantados }\end{array}$ & $\begin{array}{c}0 \% \\
25 \% \\
50 \% \\
75 \% \\
100 \%\end{array}$ & $\begin{array}{c}0 \\
75 \\
150 \\
225 \\
300\end{array}$ \\
\hline EC7 & $\begin{array}{l}\text { Programa de redução de emissão de gases de efeito estufa } \\
\text { 1) Não há iniciativas de redução } \\
\text { 2) Programa em preparação } \\
\text { 3) Redução de emissões diretas de fontes de controle da } \\
\text { universidade } \\
\text { 4) Redução de emissões indiretas da energia elétrica } \\
\text { adquirida } \\
\text { 5) Redução de emissões indiretas das atividades da } \\
\text { universidade }\end{array}$ & $\begin{array}{c}0 \% \\
25 \% \\
50 \% \\
75 \% \\
100 \%\end{array}$ & $\begin{array}{c}0 \\
50 \\
100 \\
150 \\
200\end{array}$ \\
\hline EC8 & $\begin{array}{l}\text { Pegada de carbono } \\
\text { 1) }>2,05 \mathrm{t} / \text { pessoa } \\
\text { 2) } 1,11-2,05 \mathrm{t} / \text { pessoa } \\
\text { 3) } 0,42-1,11 \mathrm{t} / \text { pessoa } \\
\text { 4) } 0,10-0,42 \mathrm{t} / \text { pessoa }(0,11 \mathrm{t} / \text { pessoa }) \\
\text { 5) }<0,10 \mathrm{t} \text { pessoa }\end{array}$ & $\begin{array}{c}0 \% \\
25 \% \\
50 \% \\
75 \% \\
100 \% \\
\end{array}$ & $\begin{array}{c}0 \\
75 \\
150 \\
225 \\
300\end{array}$ \\
\hline
\end{tabular}

Fonte: Adaptação de Falcão (2018).

$\mathrm{Na}$ avaliação da categoria Ensino e pesquisa, quadro 2, dos sete indicadores quatro obtiveram desempenhos suficientes e três obtiveram desempenhos não suficientes, sendo um com desempenho $0 \%$ : não haver orçamento específico à pesquisa sobre sustentabilidade). A estimativa do indicador que quantifica as publicações sobre sustentabilidade resultou ótima - retornos no Google Acadêmico -, porém necessita de confirmação, bem como a estimativa sobre o oferecimento de disciplinas sobre sustentabilidade. $\mathrm{O}$ ideal seria que a universidade oficializasse esses dados, requerendo de cada curso a análise de sustentabilidade de seu currículo e de cada docente sua produção indexada sobre sustentabilidade. Ainda poderia estimular a criação de organizações estudantis sobre sustentabilidade nas unidades de ensino, o que poderia levar à realização de diferentes eventos sobre sustentabilidade.

Quadro 2 -

Indicadores na categoria Ensino e pesquisa.

\begin{tabular}{|c|c|c|c|}
\hline Código & \multicolumn{1}{|c|}{ Indicador } & Nível & Pontuação \\
\hline \multirow{5}{*}{ ED1 } & Disciplinas sobre sustentabilidade & & \\
& 1) $<1 \%$ & $25 \%$ & 0 \\
& 2) $1-3 \%$ & $50 \%$ & 75 \\
& 3) $3-8 \%(4 \%)$ & $75 \%$ & 225 \\
& 4) $8-17 \%$ & $100 \%$ & 300 \\
\hline \multirow{5}{*}{ ED2 } & 5) $>17 \%$ & & \\
& Orçamento para pesquisa sobre sustentabilidade & $0 \%$ & 0 \\
& 1) $<1 \%(0 \%)$ & $25 \%$ & 75 \\
& 2) $1-7 \%$ & $50 \%$ & 150 \\
& 3) $7-14 \%$ & $75 \%$ & 225 \\
& 4) $14-30 \%$ & $100 \%$ & 300 \\
\hline
\end{tabular}




\begin{tabular}{|c|c|c|c|}
\hline ED3 & $\begin{array}{ll}\text { Publicações sobre sustentabilidade } \\
\text { 1) } 0 \\
\text { 2) } 1-20 \\
\text { 3) } & 21-83 \\
\text { 4) } & 84-300 \\
\text { 5) } & >300(2.223)\end{array}$ & $\begin{array}{c}0 \% \\
25 \% \\
50 \% \\
75 \% \\
100 \% \\
\end{array}$ & $\begin{array}{r}0 \\
75 \\
150 \\
225 \\
300\end{array}$ \\
\hline ED4 & $\begin{array}{l}\text { Eventos sobre sustentabilidade } \\
\text { 1) } 0 \\
\text { 2) } 1-4(1) \\
\text { 3) } 5-17 \\
\text { 4) } 18-47 \\
\text { 5) }>47\end{array}$ & $\begin{array}{l}0 \% \\
25 \% \\
50 \% \\
75 \% \\
100 \%\end{array}$ & $\begin{array}{r}0 \\
75 \\
150 \\
225 \\
300\end{array}$ \\
\hline ED5 & $\begin{array}{l}\text { Organizações estudantis sobre sustentabilidade } \\
\text { 1) } 0 \\
\text { 2) } 1-2(1) \\
\text { 3) } 3-4 \\
\text { 4) } 5-10 \\
\text { 5) }>10\end{array}$ & $\begin{array}{l}0 \% \\
25 \% \\
50 \% \\
75 \% \\
100 \%\end{array}$ & $\begin{array}{r}0 \\
75 \\
150 \\
225 \\
300\end{array}$ \\
\hline ED6 & $\begin{array}{l}\text { Site sobre sustentabilidade } \\
\text { 1) Não há } \\
\text { 2) Em construção } \\
\text { 3) Há site } \\
\text { 4) Há site atualizado ocasionalmente } \\
\text { 5) Há site atualizado regularmente }\end{array}$ & $\begin{array}{l}0 \% \\
25 \% \\
50 \% \\
75 \% \\
100 \%\end{array}$ & $\begin{array}{c}0 \\
50 \\
100 \\
150 \\
200\end{array}$ \\
\hline ED7 & $\begin{array}{l}\text { Relatório sobre sustentabilidade } \\
\text { 1) Não há } \\
\text { 2) Em preparação } \\
\text { 3) Há relatório } \\
\text { 4) Há relatório atualizado anualmente } \\
\text { 5) Há relatório atualizado anualmente, acessível }\end{array}$ & $\begin{array}{c}0 \% \\
25 \% \\
50 \% \\
75 \% \\
100 \%\end{array}$ & $\begin{array}{c}0 \\
25 \\
50 \\
75 \\
100\end{array}$ \\
\hline
\end{tabular}

Fonte: Adaptação de Falcão (2018).

O quadro 3 apresenta a avaliação da categoria Mobilidade. Dos oito indicadores cinco obtiveram desempenhos suficientes e três obtiveram desempenhos não suficientes, sendo três com desempenho $0 \%$. O indicador TR3 - Programa de utilização de veículos zero emissões - obteve $0 \%$ da pontuação, mas passaria a $100 \%$ com o retorno do sistema de compartilhamento de bicicletas da universidade, encerrado por falta de manutenção. A melhoria nessa categoria passa pela institucionalização de um programa de desestímulo ao uso de veículos privados para deslocamentos ao campus, o que demandaria atuar junto ao município para melhoria das ciclovias e do transporte público ao campus.

\section{Quadro 3 -}

Indicadores na categoria Mobilidade.

\begin{tabular}{|c|c|c|c|}
\hline Código & \multicolumn{1}{|c|}{ Indicador } & Nível & Pontuação \\
\hline \multirow{5}{*}{ TR1 } & Veículos por população do campus & & \\
& 1) $>$ 1 veículo/pessoa & $0 \%$ & 0 \\
& 2) $0,5-1$ veículo/pessoa & $25 \%$ & 50 \\
& 3) $0,125-0,5$ veículo/pessoa (0,376 veículo/pessoa) & $50 \%$ & 100 \\
& 4) $0,045-0,125$ veículo/pessoa & $75 \%$ & 150 \\
& 5) $<0,045$ veículo/pessoa & $100 \%$ & 200 \\
\hline
\end{tabular}




\begin{tabular}{|c|c|c|c|}
\hline TR2 & $\begin{array}{l}\text { Serviço interno de transporte } \\
\text { 1) Não há envolvimento da universidade } \\
\text { 2) Terceirizado, subsidiado parcialmente pela universidade } \\
\text { 3) Oferecido regularmente pela universidade, mas não } \\
\text { gratuitamente } \\
\text { 4) Oferecido pela universidade, gratuitamente } \\
\text { 5) Oferecido pela universidade, gratuitamente e sem emissões }\end{array}$ & $\begin{array}{l}0 \% \\
25 \% \\
50 \% \\
75 \% \\
100 \%\end{array}$ & $\begin{array}{c}0 \\
75 \\
150 \\
225 \\
300\end{array}$ \\
\hline TR3 & $\begin{array}{l}\text { Programa de utilização de veículos zero emissões } \\
\text { 1) Não há iniciativas de disponibilização } \\
\text { 2) Planejamento mostrou ser inviável } \\
\text { 3) Veículos disponibilizados, mas não pela universidade } \\
\text { 4) Veículos disponibilizados pela universidade, mas não } \\
\text { gratuitamente } \\
\text { 5) Veículos disponibilizados pela universidade gratuitamente }\end{array}$ & $\begin{array}{l}0 \% \\
25 \% \\
50 \% \\
75 \% \\
100 \%\end{array}$ & $\begin{array}{c}0 \\
50 \\
100 \\
150 \\
200\end{array}$ \\
\hline TR4 & $\begin{array}{l}\text { Veículos zero emissões por população do campus } \\
\text { 1) }<0,002 \text { veículo/pessoa } \\
\text { 2) } 0,002-0,004 \text { veículo/pessoa } \\
\text { 3) } 0,004-0,008 \text { veículo/pessoa } \\
\text { 4) } 0,008-0,02 \text { veículo/pessoa } \\
\text { 5) }>0,02 \text { veículo/pessoa (0,035 bicicleta/pessoa) }\end{array}$ & $\begin{array}{l}0 \% \\
25 \% \\
50 \% \\
75 \% \\
100 \%\end{array}$ & $\begin{array}{c}0 \\
50 \\
100 \\
150 \\
200\end{array}$ \\
\hline TR5 & 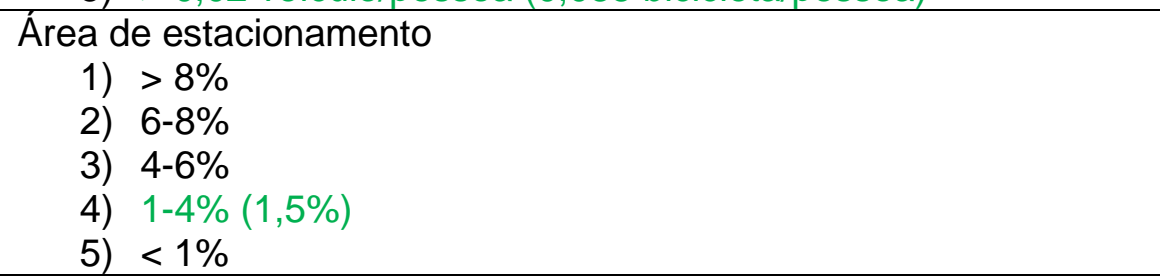 & $\begin{array}{l}0 \% \\
25 \% \\
50 \% \\
75 \% \\
100 \% \\
\end{array}$ & $\begin{array}{c}0 \\
50 \\
100 \\
150 \\
200\end{array}$ \\
\hline TR6 & $\begin{array}{l}\text { Programa de redução de áreas de estacionamento } \\
\text { 1) Não há iniciativas de redução } \\
\text { 2) Programa em preparação } \\
\text { 3) Menos de } 10 \% \text { de redução } \\
\text { 4) Entre } 10 \text { e } 30 \% \text { de redução } \\
\text { 5) Redução de mais de } 30 \% \text { ou restrição de estacionamento }\end{array}$ & $\begin{array}{l}0 \% \\
25 \% \\
50 \% \\
75 \% \\
100 \%\end{array}$ & $\begin{array}{c}0 \\
50 \\
100 \\
150 \\
200\end{array}$ \\
\hline TR7 & $\begin{array}{l}\text { Programa de desestímulo ao uso de veículos privados } \\
\text { 1) Não há iniciativas de desestímulo } \\
\text { 2) Uma iniciativa existente } \\
\text { 3) Duas iniciativas existentes } \\
\text { 4) Três iniciativas existentes } \\
\text { 5) Mais de três iniciativas existentes }\end{array}$ & $\begin{array}{l}0 \% \\
25 \% \\
50 \% \\
75 \% \\
100 \%\end{array}$ & $\begin{array}{c}0 \\
50 \\
100 \\
150 \\
200\end{array}$ \\
\hline TR8 & $\begin{array}{l}\text { Circulação pedestre } \\
\text { 1) Não há vias de pedestres } \\
\text { 2) Há vias de pedestres } \\
\text { 3) Há vias projetadas para segurança } \\
\text { 4) Há vias projetadas para segurança e conveniência } \\
\text { 5) Há vias projetadas para segurança, conveniência e } \\
\text { acessibilidade }\end{array}$ & $\begin{array}{c}0 \% \\
25 \% \\
50 \% \\
75 \% \\
100 \%\end{array}$ & $\begin{array}{c}0 \\
75 \\
150 \\
225 \\
300\end{array}$ \\
\hline
\end{tabular}

Fonte: Adaptação de Falcão (2018).

A categoria Resíduos, quadro 4, foi o destaque da avaliação. Dos seis indicadores quatro obtiveram desempenhos suficientes e dois obtiveram desempenhos não suficientes, mas nenhum com desempenho $0 \%$. No campus I é ativa a gestão de resíduos e a coleta de resíduos orgânicos está em consolidação. A melhoria nessa categoria passa pela atuação junto ao município para a coleta do esgoto sanitário, uma vez que não há rede coletora de esgoto: os prédios da universidade utilizam o sistema de tanques sépticos. 
Quadro 4 -

Indicadores na categoria Resíduos.

\begin{tabular}{|c|c|c|c|}
\hline Código & Indicador & Nível & Pontuação \\
\hline WS1 & $\begin{array}{l}\text { Reciclagem } \\
\text { 1) Não há } \\
\text { 2) } 1-25 \% \\
\text { 3) } 25-50 \% \\
\text { 4) } 50-75 \% \\
\text { 5) }>75 \%\end{array}$ & $\begin{array}{r}0 \% \\
25 \% \\
50 \% \\
75 \% \\
100 \%\end{array}$ & $\begin{array}{c}0 \\
75 \\
150 \\
225 \\
300\end{array}$ \\
\hline WS2 & $\begin{array}{l}\text { Programa de redução do uso de papéis e plásticos } \\
\text { 1) Não há iniciativas de redução } \\
\text { 2) Uma iniciativa existente } \\
\text { 3) Duas iniciativas existentes } \\
\text { 4) Três iniciativas existentes } \\
\text { 5) Mais de três iniciativas existentes } \\
\end{array}$ & $\begin{array}{r}0 \% \\
25 \% \\
50 \% \\
75 \% \\
100 \% \\
\end{array}$ & $\begin{array}{c}0 \\
75 \\
150 \\
225 \\
300 \\
\end{array}$ \\
\hline WS3 & $\begin{array}{l}\text { Gerenciamento dos resíduos orgânicos } \\
\text { 1) Lixão } \\
\text { 2) } 1-25 \%(15 \%) \\
\text { 3) } 25-50 \% \\
\text { 4) } 50-75 \% \\
\text { 5) }>75 \%\end{array}$ & $\begin{array}{c}0 \% \\
25 \% \\
50 \% \\
75 \% \\
100 \% \\
\end{array}$ & $\begin{array}{c}0 \\
75 \\
150 \\
225 \\
300\end{array}$ \\
\hline WS4 & $\begin{array}{l}\text { Gerenciamento dos rejeitos } \\
\text { 1) Queimados ao ar livre } \\
\text { 2) } 1-25 \% \\
\text { 3) } 25-50 \% \\
\text { 4) } 50-75 \% \\
\text { 5) }>75 \%\end{array}$ & $\begin{array}{r}0 \% \\
25 \% \\
50 \% \\
75 \% \\
100 \% \\
\end{array}$ & $\begin{array}{c}0 \\
75 \\
150 \\
225 \\
300 \\
\end{array}$ \\
\hline WS5 & $\begin{array}{l}\text { Gerenciamento dos resíduos perigosos } \\
\text { 1) Não há } \\
\text { 2) } 1-25 \% \\
\text { 3) } 25-50 \% \\
\text { 4) } 50-75 \% \\
\text { 5) }>75 \%\end{array}$ & $\begin{array}{r}0 \% \\
25 \% \\
50 \% \\
75 \% \\
100 \%\end{array}$ & $\begin{array}{c}0 \\
75 \\
150 \\
225 \\
300\end{array}$ \\
\hline WS6 & $\begin{array}{l}\text { Tratamento dos esgotos } \\
\text { 1) Lançados sem tratamento } \\
\text { 2) Tratamento convencional } \\
\text { 3) Tratamento avançado } \\
\text { 4) Tratamento para downcycling } \\
\text { 5) Tratamento para upcycling } \\
\end{array}$ & $\begin{array}{r}0 \% \\
25 \% \\
50 \% \\
75 \% \\
100 \% \\
\end{array}$ & $\begin{array}{c}0 \\
75 \\
150 \\
225 \\
300\end{array}$ \\
\hline
\end{tabular}

Fonte: Adaptação de Falcão (2018).

No quadro 5 consta a avaliação da categoria Espaço físico. Dos seis indicadores três obtiveram desempenhos suficientes e três obtiveram desempenhos não suficientes, sendo dois com desempenho $0 \%$. Não há orçamento específico da universidade às ações de sustentabilidade. Embora o indicador de área verde não tenha pontuado bem, a área verde atual parece atender à demanda da população de Santa Maria: o campus é considerado um parque da cidade. 
Quadro 5 -

Indicadores na categoria Espaço físico.

\begin{tabular}{|c|c|c|c|}
\hline Código & Indicador & Nível & Pontuação \\
\hline Sl1 & $\begin{aligned} & \text { Área livre } \\
& \text { 1) }<1 \% \\
& \text { 2) } 1-70 \% \\
& \text { 3) } 70-85 \% \\
& \text { 4) } 85-92 \% \\
& \text { 5) }>92 \%(96 \%)\end{aligned}$ & $\begin{array}{l}0 \% \\
25 \% \\
50 \% \\
75 \% \\
100 \%\end{array}$ & $\begin{array}{c}0 \\
75 \\
150 \\
225 \\
300\end{array}$ \\
\hline $\mathrm{S} 12$ & \begin{tabular}{|l|} 
Área de mata \\
1) $<1 \%$ \\
2) $1-2 \%$ \\
3) $2-9 \%$ \\
4) $9-22 \%(15 \%)$ \\
5) $>22 \%$ \\
\end{tabular} & $\begin{array}{c}0 \% \\
25 \% \\
50 \% \\
75 \% \\
100 \% \\
\end{array}$ & $\begin{array}{c}0 \\
50 \\
100 \\
150 \\
200\end{array}$ \\
\hline $\mathrm{S} 13$ & $\begin{aligned} \text { Área verde } \\
\text { 1) }<1 \% \\
\text { 2) } 1-9 \%(3 \%) \\
\text { 3) } 9-19 \% \\
\text { 4) } 19-34 \% \\
\text { 5) }>34 \%\end{aligned}$ & $\begin{array}{c}0 \% \\
25 \% \\
50 \% \\
75 \% \\
100 \%\end{array}$ & $\begin{array}{c}0 \\
75 \\
150 \\
225 \\
300\end{array}$ \\
\hline SI4 & $\begin{array}{l}\text { Área de drenagem de águas } \\
\text { 1) }<1 \%(0 \%) \\
\text { 2) } 1-2 \% \\
\text { 3) } 2-14 \% \\
\text { 4) } 14-29 \% \\
\text { 5) }>29 \%\end{array}$ & $\begin{array}{c}0 \% \\
25 \% \\
50 \% \\
75 \% \\
100 \%\end{array}$ & $\begin{array}{c}0 \\
50 \\
100 \\
150 \\
200\end{array}$ \\
\hline SI5 & $\begin{array}{l}\text { Área livre por população do campus } \\
\text { 1) }<1 \mathrm{~m}^{2} / \text { pessoa } \\
\text { 2) } 1-3 \mathrm{~m}^{2} / \text { pessoa } \\
\text { 3) } 3-27 \mathrm{~m}^{2} \text { pessoa } \\
\text { 4) } 27-83 \mathrm{~m}^{2} / \text { pessoa } \\
\text { 5) }>83 \mathrm{~m}^{2} \text { pessoa }\left(209,79 \mathrm{~m}^{2} / \text { pessoa }\right)\end{array}$ & $\begin{array}{l}0 \% \\
25 \% \\
50 \% \\
75 \% \\
100 \%\end{array}$ & $\begin{array}{c}0 \\
75 \\
150 \\
225 \\
300\end{array}$ \\
\hline SI6 & $\begin{array}{l}\text { Orçamento para ações de sustentabilidade } \\
\text { 1) }<1 \%(0 \%) \\
\text { 2) } 1-3 \% \\
\text { 3) } 3-5 \% \\
\text { 4) } 5-10 \% \\
\text { 5) }>10 \%\end{array}$ & $\begin{array}{c}0 \% \\
25 \% \\
50 \% \\
75 \% \\
100 \%\end{array}$ & $\begin{array}{c}0 \\
50 \\
100 \\
150 \\
200\end{array}$ \\
\hline
\end{tabular}

Fonte: Adaptação de Falcão (2018).

Por fim, no quadro 6 é apresentada a avaliação da categoria Água, destaque negativo da avaliação. Dos quatro indicadores um obteve desempenho suficiente e três obtiveram desempenhos não suficientes, todos com desempenho $0 \%$. Com exceção do Hospital Universitário, abastecido pela Companhia Riograndense de Saneamento, todo o campus é abastecido por poços artesianos, cuja água é bombeada a reservatórios e recebem cloração. A melhoria nessa categoria passa pela institucionalização de programas de conservação e reúso de água. A maior parte dos prédios não possui hidrômetro, então não se conhece a quantidade de água consumida. 
Quadro 6 -

Indicadores na categoria Água.

\begin{tabular}{|c|c|c|c|}
\hline Código & Indicador & Nível & Pontuação \\
\hline WR1 & $\begin{array}{l}\text { Programa de conservação de água } \\
\text { 1) Não há iniciativas } \\
\text { 2) Programa em preparação ou 1-25\% de conservação } \\
\text { 3) Programa em implantação inicial ou 25-50\% de } \\
\text { conservação } \\
\text { 4) } 50-75 \% \text { de conservação } \\
\text { 5) }>75 \% \text { de conservação }\end{array}$ & $\begin{array}{l}0 \% \\
25 \% \\
50 \% \\
75 \% \\
100 \%\end{array}$ & $\begin{array}{c}0 \\
75 \\
150 \\
225 \\
300\end{array}$ \\
\hline WR2 & $\begin{array}{l}\text { Programa de reúso de água } \\
\text { 1) Não há iniciativas } \\
\text { 2) Programa em preparação ou 1-25\% de reúso } \\
\text { 3) Programa em implantação inicial ou } 25-50 \% \text { de reúso } \\
\text { 4) } 50-75 \% \text { de reúso } \\
\text { 5) }>75 \% \text { de reúso }\end{array}$ & $\begin{array}{c}0 \% \\
25 \% \\
50 \% \\
75 \% \\
100 \% \\
\end{array}$ & $\begin{array}{c}0 \\
75 \\
150 \\
225 \\
300 \\
\end{array}$ \\
\hline WR3 & $\begin{array}{l}\text { Dispositivos economizadores de água } \\
\text { 1) Nenhuma iniciativa de instalação } \\
\text { 2) Instalações em preparação ou em 1-25\% das instalações } \\
\text { 3) Em } 25-50 \% \text { das instalações } \\
\text { 4) Em } 50-75 \% \text { das instalações } \\
\text { 5) Em mais de } 75 \% \text { das instalações }\end{array}$ & $\begin{array}{l}0 \% \\
25 \% \\
50 \% \\
75 \% \\
100 \%\end{array}$ & $\begin{array}{c}0 \\
50 \\
100 \\
150 \\
200\end{array}$ \\
\hline WR4 & $\begin{array}{l}\text { Consumo de água tratada } \\
\text { 1) Não há água tratada disponível } \\
\text { 2) } 1-25 \% \text { da água consumida } \\
\text { 3) } 25-50 \% \text { da água consumida } \\
\text { 4) } 50-75 \% \text { da água consumida } \\
\text { 5) }>75 \% \text { da água consumida }\end{array}$ & $\begin{array}{c}0 \% \\
25 \% \\
50 \% \\
75 \% \\
100 \% \\
\end{array}$ & $\begin{array}{c}0 \\
50 \\
100 \\
150 \\
200 \\
\end{array}$ \\
\hline
\end{tabular}

Fonte: Adaptação de Falcão (2018).

$\mathrm{Na}$ tabela 1 reúnem-se as notas de cada categoria e a medida do desempenho sustentável do campus I da UFSM: 4,8. Considerando que na universidade a nota mínima de aprovação é cinco, o desempenho sustentável atual do campus medido pelo modelo GreenMetric é não suficiente. Quanto às categorias do modelo quatro das seis obtiveram desempenhos aceitáveis, mas apenas a categoria Resíduos obteve desempenho acima dos $70 \%$ desejáveis.

Tabela 1 -

Medida do desempenho sustentável do campus I da UFSM.

\begin{tabular}{|c|c|c|c|c|c|}
\hline \multirow{2}{*}{ Categoria } & \multirow{2}{*}{$\begin{array}{l}\text { Pontuação } \\
\text { possível }\end{array}$} & \multirow{2}{*}{ Peso } & \multicolumn{3}{|c|}{ UFSM } \\
\hline & & & Pontuação & Desempenho & Nota $(1-10)$ \\
\hline $\begin{array}{l}\text { Energia e Mudanças } \\
\text { Climáticas }\end{array}$ & 2.100 & $21 \%$ & 575 & $27 \%$ & 2,7 \\
\hline Ensino e Pesquisa & 1.800 & $18 \%$ & 900 & $50 \%$ & 5,0 \\
\hline Mobilidade & 1.800 & $18 \%$ & 900 & $50 \%$ & 5,0 \\
\hline Resíduos & 1.800 & $18 \%$ & 1.350 & $75 \%$ & 7,5 \\
\hline Espaço Físico & 1.500 & $15 \%$ & 825 & $55 \%$ & 5,5 \\
\hline Água & 1.000 & $10 \%$ & 200 & $20 \%$ & 2,0 \\
\hline Total & 10.000 & $100 \%$ & 4.750 & \multirow{2}{*}{$47,5 \%$} & \multirow{2}{*}{4,8} \\
\hline \multicolumn{4}{|c|}{ Média ponderada } & & \\
\hline
\end{tabular}

Fonte: Adaptação de Falcão (2018). 
$\mathrm{Na}$ realidade, obter um desempenho sustentável acima de $70 \%$ parece difícil: apenas 80 das 719 universidades participantes do ranking 2018 (11\%) obtiveram tal desempenho e menos da metade das participantes (42\%) atingiu desempenho sustentável acima de 50\%. Quanto às universidades brasileiras apenas 7 das 23 participantes (30\%) atingiram desempenho sustentável acima de 50\%, com duas com nota acima de sete: Universidade de São Paulo $(7,75)$ e Universidade Federal de Lavras $(7,48)$ (UI Greenmetric, 2018).

Vê-se na tabela 2 que as universidades mais bem posicionadas tiveram, em média, desempenhos acima de $90 \%$ nas categorias Ensino e pesquisa (94,2\%) e Resíduos (93,3\%). A UFSM também teve seu melhor desempenho na categoria Resíduos: $75 \%$, acima da média das dez universidades brasileiras (61,3\%). Como já comentado, seu ponto mais fraco nessa categoria é o tratamento dos esgotos, pois não há rede coletora de esgoto sanitário. Para comparação a Universidade de São Paulo, melhor brasileira posicionada, possui rede de água e esgoto atendidas pela Companhia de Saneamento Básico do Estado de São Paulo, além de sua Superintendência de Gestão Ambiental (USP, 2018) possuir grupos de trabalho para água e efluentes e para resíduos, com iniciativas como inventários de resíduos e medição setorizada com rateio de despesas relativas a água e esgoto, o que a UFSM não possui. Já na categoria Ensino e pesquisa, embora tenha obtido desempenho $50 \%$, a UFSM ficou 12,6 pontos percentuais abaixo da média nacional, sendo seu ponto mais fraco a inexistência de orçamento dedicado à pesquisa sobre sustentabilidade. Nessa categoria a brasileira melhor posicionada foi a Universidade Federal de Viçosa, atuante na inserção da cultura da sustentabilidade na instituição (UFV, 2019). Na média nacional o melhor desempenho das dez primeiras posicionadas foi na categoria Espaço físico (69,8\%), 14,8 pontos percentuais acima do da UFSM, e o pior desempenho foi na categoria Mobilidade $(50,4 \%)$, na média da UFSM (50\%). Exceto pela categoria Resíduos o desempenho da UFSM foi abaixo da média nacional.

Tabela 2 -

Desempenho das dez melhores universidades internacionais e brasileiras em 2018.

\begin{tabular}{|c|c|c|c|c|c|c|c|c|}
\hline \multirow{2}{*}{ N.․․ } & \multirow{2}{*}{ Universidade } & \multicolumn{6}{|c|}{ Categoria } & \multirow{2}{*}{ Média } \\
\hline & & Ener. & Ensi. & Mobi. & Resíd. & Espa. & Água & \\
\hline 1 & Wageningen University (Países Baixos) & $82,1 \%$ & $100,0 \%$ & $86,1 \%$ & $100,0 \%$ & $83,3 \%$ & $100,0 \%$ & $91,3 \%$ \\
\hline 2 & University of Nottingham (Reino Unido) & $79,8 \%$ & $95,8 \%$ & $80,6 \%$ & $87,5 \%$ & $78,3 \%$ & $100,0 \%$ & $86,0 \%$ \\
\hline 3 & University of California Davis (EUA) & $65,5 \%$ & $87,5 \%$ & $83,3 \%$ & $95,8 \%$ & $93,3 \%$ & $100,0 \%$ & $85,8 \%$ \\
\hline 4 & University of Oxford (Reino Unido) & $77,4 \%$ & $91,7 \%$ & $88,9 \%$ & $91,7 \%$ & $76,7 \%$ & $85,0 \%$ & $85,3 \%$ \\
\hline 5 & Nottingham Trent University (Reino Unido) & $79,8 \%$ & $100,0 \%$ & $77,8 \%$ & $100,0 \%$ & $81,7 \%$ & $55,0 \%$ & $84,5 \%$ \\
\hline 6 & Umwelt-Campus Birkenfeld (Alemanha) & $81,0 \%$ & $95,8 \%$ & $70,8 \%$ & $83,3 \%$ & $90,0 \%$ & $80,0 \%$ & $83,5 \%$ \\
\hline 7 & University of Groningen (Países Baixos) & $73,8 \%$ & $87,5 \%$ & $86,1 \%$ & $87,5 \%$ & $73,3 \%$ & $100,0 \%$ & $83,5 \%$ \\
\hline 8 & Bangor University (Reino Unido) & $71,4 \%$ & $100,0 \%$ & $94,4 \%$ & $91,7 \%$ & $83,3 \%$ & $42,5 \%$ & $83,3 \%$ \\
\hline 9 & University College Cork (Irlanda) & $70,2 \%$ & $91,7 \%$ & $91,7 \%$ & $95,8 \%$ & $76,7 \%$ & $60,0 \%$ & $82,5 \%$ \\
\hline \multirow[t]{2}{*}{10} & University of Connecticut (EUA) & $64,3 \%$ & $91,7 \%$ & $80,6 \%$ & $100,0 \%$ & $80,0 \%$ & $70,0 \%$ & $81,5 \%$ \\
\hline & Média das dez primeiras & $\%$ & $2 \%$ & $0 \%$ & $3 \%$ & $\%$ & $3 \%$ & $84,7 \%$ \\
\hline 23 & Universidade de São Paulo & $64,3 \%$ & $76,4 \%$ & $76,4 \%$ & $83,3 \%$ & $96,7 \%$ & $70,0 \%$ & $77,5 \%$ \\
\hline 38 & Universidade Federal de Lavras & $61,9 \%$ & $80,6 \%$ & $68,1 \%$ & $79,2 \%$ & $91,7 \%$ & $70,0 \%$ & $74,8 \%$ \\
\hline 100 & Universidade Positivo & $75,0 \%$ & $62,5 \%$ & $43,1 \%$ & $79,2 \%$ & $66,7 \%$ & $77,5 \%$ & $66,8 \%$ \\
\hline 154 & Centro Universitário do Rio Grande do Norte & $54,8 \%$ & $63,9 \%$ & $45,8 \%$ & $54,2 \%$ & $75,0 \%$ & $70,0 \%$ & $59,3 \%$ \\
\hline 220 & Universidade Federal de Viçosa & $53,6 \%$ & $87,5 \%$ & $33,3 \%$ & $50,0 \%$ & $45,0 \%$ & $62,5 \%$ & $55,0 \%$ \\
\hline 283 & Instituto Federal do Sul de MG & $46,4 \%$ & $54,2 \%$ & $51,4 \%$ & $45,8 \%$ & $63,3 \%$ & $42,5 \%$ & $50,8 \%$ \\
\hline 297 & Pontifícia Universidade Católica do RJ & $32,1 \%$ & $45,8 \%$ & $54,2 \%$ & $66,7 \%$ & $66,7 \%$ & $35,0 \%$ & $50,3 \%$ \\
\hline 311 & Universidade Federal do Triângulo Mineiro & $48,8 \%$ & $38,9 \%$ & $40,3 \%$ & $58,3 \%$ & $61,7 \%$ & $50,0 \%$ & $49,3 \%$ \\
\hline
\end{tabular}

\begin{tabular}{|l|l|l|l|l|r|}
\hline Regae: Rev. Gest. Aval. Educ. & Santa Maria & v. 9 & n. 18 & Pub. contínua 2020 & p. 1-16
\end{tabular}




\begin{tabular}{r|l|l|l|l|l|l|l|l}
\hline 312 & Pontifícia Universidade Católica do RS & $42,9 \%$ & $58,3 \%$ & $38,9 \%$ & $45,8 \%$ & $68,3 \%$ & $42,5 \%$ & $49,3 \%$ \\
\hline 350 & Universidade Federal do Rio Grande do Sul & $29,8 \%$ & $58,3 \%$ & $52,8 \%$ & $50,0 \%$ & $63,3 \%$ & $30,0 \%$ & $47,8 \%$ \\
\hline & Média das dez primeiras brasileiras & $51,0 \%$ & $62,6 \%$ & $50,4 \%$ & $61,3 \%$ & $69,8 \%$ & $55,0 \%$ & $58,1 \%$ \\
\hline & Desempenho da UFSM & $27,0 \%$ & $50,0 \%$ & $50,0 \%$ & $75,0 \%$ & $55,0 \%$ & $20,0 \%$ & $47,5 \%$ \\
\hline
\end{tabular}

Fonte: Adaptação de GreenMetric (2019).

Contudo, ao posicionar no ranking 2018 o desempenho estimado para a UFSM, sua pontuação a posicionaria em empate com cinco universidades nas posições entre 351 e 355, entre elas a Universidade Federal do Rio de Janeiro, a $11^{\text {a }}$ entre as universidades brasileiras. Relativizando desta maneira, não é um desempenho ruim. E está em processo uma reestruturação do planejamento ambiental da universidade, com a criação de uma coordenadoria de gestão ambiental. Assim, embora hoje a universidade não seja objetivamente sustentável, ela parece estar em direção à sustentabilidade.

\section{Considerações finais}

A questão deste trabalho foi a medida da sustentabilidade do campus I da UFSM, a qual, pelo modelo de medição do desempenho sustentável para universidades GreenMetric, foi encontrada 47,5\%. Abaixo de 50\%, não é um desempenho suficiente. Porém, dentro do contexto do ranking e do último desempenho das universidades brasileiras participantes, não se pode considerar um desempenho de todo ruim.

Espera-se que este trabalho estimule o debate acadêmico e a autoavaliação sobre sustentabilidade na UFSM e que estimule o seu ingresso no ranking universitário internacional de ações de sustentabilidade.

\section{Referências}

CENTRO SEBRAE DE SUSTENTABILIDADE. Tendências de sustentabilidade para os pequenos negócios. 2013.

Disponível

em

http://sustentabilidade.sebrae.com.br/sites/Sustentabilidade/Para\%E2\%80\%93sua\%E2\%8 0\%93Empresa/Nucleo-Inteligencia/Tend\%C3\%AAncias-de-sustentabilidade-parapequenos-neg\%C3\%B3cios. Acesso em 3 out. 2019.

DAGILIŪTĖ, Renata; LIOBIKIENĖ, Genovaitė; MINELGAITÉ, Audronè. Sustainability at universities: students' perceptions from green and non-green universities. Journal of Cleaner Production, v. 181, 2018, p. 473-482.

HARRINGTON, James. Aperfeiçoando processos empresariais. São Paulo: Makron Books, 1993.

HOLDEN, Erling; LINNERUD, Kristin; BANISTER, David. Sustainable development: Our Common Future revisited. Global Environmental Change, v. 26, 2014, p. 130-139. Disponível em https://doi.org/10.1016/i.gloenvcha.2014.04.006. Acesso em 3 out. 2019.

NAÇÕES UNIDAS DO BRASIL. A ONU e o meio ambiente. 2019. Disponível em https://nacoesunidas.org/acao/meio-ambiente. Acesso em 3 out. 2019.

O GLOBO. Brasileiro valoriza produtos mais sustentáveis e embalagens com selos ambientais. $O$ Globo, 13 nov. 2017. Disponível em https://oglobo.globo.com/economia/defesa-do-consumidor/brasileiro-valoriza-produtosmais-sustentaveis-embalagens-com-selos-ambientais-22058923\#ixzz5PPC91AQM. Acesso em 3 out. 2019. 
REDE UNIVERSITÁRIA DE PROGRAMAS DE EA PARA SOCIEDADES SUSTENTÁVEIS (RUPEA). Mapeamento da educação ambiental em instituições brasileiras de educação superior. Brasília: Órgão Gestor da Política Nacional de Educação Ambiental, 2007. Disponível em http://www.mma.gov.br/estruturas/educamb/ arquivos/dt 12.pdf. Acesso em 3 out. 2019.

SARTORI, Simone; LATRONICO, Fernanda; CAMPOS, Lucila. Sustentabilidade e desenvolvimento sustentável: uma taxonomia no campo da literatura. Ambiente \& Sociedade, São Paulo, v. 17, n. 1, 2014, p. 1-22.

SEELIG FALCÃO, Marina Fonseca. Avaliação do desempenho sustentável da Cidade Universitária da UFSM pelos indicadores GreenMetric. Santa Maria: UFSM, 2018. 64f. Trabalho de conclusão de curso (Graduação em Engenharia Sanitária e Ambiental). Universidade Federal de Santa Maria.

UFSM. Guia do estudante 2015. Disponível em https://www.ufsm.br/proreitorias/prograd/wp-content/uploads/sites/342/2018/05/guiaacademicoUFSM.pdf. Acesso em 3 out. 2019.

UFSM. Plano de Desenvolvimento Institucional 2016-2026. 2016. Disponível em http://pdi.ufsm.br/images/DocPDI/00-DocumentoPDI-TextoBaseCONSU.pdf. Acesso em 3 out. 2019.

UFSM. UFSM em números. 2019. Disponível em https://portal.ufsm.br/ufsm-em-numeros. Acesso em 3 out. 2019.

UFV. Universidade inicia campanha UFVerde. 2019. Disponível em https://www2.dti.ufv.br/noticias/scripts/exibeNoticiaMulti.php?codNot=30967. Acesso em 3 out. 2019.

UI GREENMETRIC. Guideline 2018. Disponível em http://greenmetric.ui.ac.id/guidelinespage. Acesso em 3 out. 2019.

UI GREENMETRIC. Overall rankings 2018. Disponível em http://greenmetric.ui.ac.id/overall-ranking-2018-2. Acesso em 3 out. 2019.

USP. Superintendência de gestão ambiental. 2018. Disponível em http://www.sga.usp.br. Acesso em 3 out. 2019.

VALENTINI, Daiane Regina. Planejamento ambiental como base ao plano diretor do campus da UFSM/RS. Santa Maria: UFSM, 2010. 128f. Dissertação (Mestrado em Geomática). Universidade Federal de Santa Maria.

VELAZQUEZ, Luis; MUNGUIA, Nora; PLATT, Alberto; TADDEI, Jorge. Sustainable university: what can be the matter? Journal of Cleaner Production, v. 14, n. 9-11, 2006, p. 810-819.

Marina Fonseca Seelig Falcão é graduada em Engenharia Sanitária e Ambiental pela Universidade Federal de Santa Maria.

Orcid: https://orcid.org/0000-0002-2597-9417.

Endereço: Avenida Roraima 1000 - CT/UFSM - 97105-900 - Santa Maria - RS Brasil.

E-mail: marinaseelig@gmail.com. 
Andressa de Oliveira Silveira é professora no Departamento de Engenharia Sanitária e Ambiental da Universidade Federal de Santa Maria. Orcid: https://orcid.org/0000-0003-3979-2503.

Endereço: Avenida Roraima, 1000 - CT/UFSM - 97105-900 - Santa Maria - RS Brasil.

E-mail: andressa.silveira@ufsm.br.

Recebido em 4 de outubro de 2019.

Aceito em 19 de dezembro de 2019.

(c) (i) 